\title{
Isolamento de bactérias Gram-negativas em amostras de sedimento de manguezal em
}

\section{São Luís, Maranhão}

\author{
Isolation of Gram-negative bacteria from manguezal sediment samples is São Luís, Maranhão
}

Aislamiento de bactérias Gram-negativas a partir de muestras de sedimentos de manguezal em São

\section{Luís, Maranhão}

Recebido: 02/02/2022 | Revisado: 07/02/2022 | Aceito: 09/02/2022 | Publicado: 14/02/2022

\author{
Verônica Duarte da Silva \\ ORCID: https://orcid.org/0000-0001-7803-2449 \\ Universidade CEUMA, Brasil \\ E-mail: veronicadrte@gmail.com \\ Yuri Nascimento Fróes \\ ORCID: https://orcid.org/0000-0002-0928-0980 \\ Faculdade Florence, Brasil \\ E-mail: yurifroes@outlook.com \\ Joveliane de Melo Monteiro \\ ORCID: https://orcid.org/0000-0003-4762-2248 \\ Universidade CEUMA, Brasil \\ E-mail: jovelianemello53@gmail.com \\ Neemias Muniz de Souza \\ ORCID: https://orcid.org/0000-0002-8506-1747 \\ Universidade CEUMA, Brasil \\ E-mail: neemias_munizdesouza@hotmail.com \\ Neuriane Silva Lima \\ ORCID: https://orcid.org/0000-0001-5383-4840 \\ Universidade CEUMA, Brasil \\ E-mail: neuriannylima@gmail.com \\ Leila Cristina Almeida de Sousa \\ ORCID: https://orcid.org/0000-0003-3071-6782 \\ Universidade CEUMA, Brasil \\ E-mail: leila.sousa @ceuma.br \\ Anna Regina Lanner de Moura \\ ORCID: https://orcid.org/0000-0003-3595-2151 \\ Universidade CEUMA, Brasil \\ E-mail: anner4@gmail.com \\ Joicy Cortez de Sá Sousa \\ ORCID: https://orcid.org/0000-0001-8678-0244 \\ Universidade CEUMA, Brasil \\ E-mail: joicyvet@ hotmail.com \\ Fabrício Brito Silva \\ ORCID: https://orcid.org/0000-0002-9878-0206 \\ Universidade CEUMA, Brasil \\ E-mail: fabricioagro@gmail.com \\ Darlan Ferreira da Silva \\ ORCID: https://orcid.org/0000-0001-7091-8077 \\ Universidade CEUMA, Brasil \\ E-mail: darlanveggito@ hotmail.com \\ Andrea de Souza Monteiro \\ ORCID: https://orcid.org/0000-0001-6887-8192 \\ Universidade CEUMA, Brasil \\ E-mail: andreasmont@gmail.com \\ Maria Raimunda Chagas Silva \\ ORCID: https://orcid.org/0000-0002-8685-7608 \\ Universidade CEUMA, Brasil \\ E-mail: marirah@gmail.com
}

\section{Resumo}

Os sedimentos dos manguezais são muito úmidos e ricos em matéria orgânica em decomposição, formados por uma série de espécies resistentes ao fluxo das marés. Este ecossistema costeiro é formado por uma série de espécies resistentes ao fluxo das marés, com solo contendo um ambiente rico que limita a diversidade de biomas. Objetivo desse estudo foi a identificação de microrganismos e a caracterização físico-química em amostras de sedimento de dois pontos de um manguezal localizados nas proximidades de um hospital na ilha de São Luís, Maranhão. Duas 
amostras do sedimento foram coletadas em tubos apropriados, armazenadas e encaminhadas para o Laboratório de Microbiologia Ambiental na Universidade CEUMA. No laboratório, alíquotas foram retiradas para as características físico-químicas utilizando-se metodologia conforme preconiza a Empresa Brasileira de Pesquisa Agropecuária (EMBRAPA), rastreando características como granulometria, matéria orgânica, carbono orgânico, nitrato e nitrito, fosforo total e $\mathrm{pH}$. O solo foi caracterizado como orgânico, rico em nitrato, nitrito e sais minerais, com $\mathrm{pH}(6,3)$, característico do ecossistema de mangues. Foi realizado isolamento, identificação dos isolados por MALDI-TOF (do inglês, Matrix-assisted Laser Desorption/Ionization Time-Of-Flight Mass Spectrometry) e teste de susceptibilidade aos antimicrobianos utilizado metodologia de Kirby-Bauer. Foram identificadas bactérias gram-negativas, principalmente do gênero Ochrobactrum e espécies termotolerante, como Escherichia coli que são consideradas patógenos indicadores de falta de saneamento básico e que apresentou multirresistência in vitro aos antibióticos testados. Nosso estudo fortalece a ideia de mais pesquisas para avaliar a diversidade de microrganismos presentes em manguezais para incentivar e alertar sobre a preservação e controle sanitário de ecossistemas de mangue.

Palavras-chave: Sedimento; Mangue; Resistência bacteriana; Físico-químico.

\begin{abstract}
Mangrove sediments are very moist and rich in decomposition organic matter, formed by a series of species resistant to tidal flow. This coastal ecosystem is formed by a series of species resistant to tidal flow, with soil containing a rich environment that limits the diversity of biomes. The objective of this study was the identification of microorganisms and the physicochemical characterization in sediment samples from two points of a mangrove located near a hospital on the island of São Luís, Maranhão. Two sediment samples were collected in appropriate tubes, stored and sent to the Environmental Microbiology Laboratory at CEUMA University. In the laboratory, aliquots were removed for the physical-chemical characteristics using a methodology as recommended by the Brazilian Agricultural Research Company (EMBRAPA), tracking characteristics such as granulometry, organic matter, organic carbon, nitrate and nitrite, total phosphorous and $\mathrm{pH}$. The soil was characterized as organic, rich in nitrate, nitrite and mineral salts, with $\mathrm{pH}$ (6.3), characteristic of the mangrove ecosystem. Isolation, identification of MALDI-TOF isolates (Matrix-assisted Laser Desorption/Ionization Time-Of-Flight Mass Spectrometry) and antimicrobial susceptibility test used KirbyBauer methodology were performed. Gram-negative bacteria were identified, of the genus Ochrobactrum and thermotolerant species, such as Escherichia coli, which are considered pathogens that are indicators of lack of basic sanitation and that presented multiresistance in vitro to the antibiotics tested. Our study strengthens the idea of further research to evaluate the diversity of microorganisms present in mangroves to encourage and warn about the preservation and sanitary control of mangrove ecosystems.
\end{abstract}

Keywords: Sediment; Mangrove; Drug resistance; Physico-chemical.

\title{
Resumen
}

Los sedimentos de manglar son muy húmedos y ricos en materia orgánica de descomposición, formados por una serie de especies resistentes al flujo de las mareas. Este ecosistema costero está formado por una serie de especies resistentes al flujo de las mareas, con un suelo que contiene un ambiente rico que limita la diversidad de biomas. El objetivo de este estudio fue la identificación de microorganismos y la caracterización fisicoquímica en muestras de sedimentos de dos puntos de un manglar ubicado cerca de un hospital en la isla de São Luís, Maranhão. Se recogieron dos muestras de sedimentos en tubos apropiados, se almacenaron y se enviaron al Laboratorio de Microbiología Ambiental de la Universidad CEUMA. En el laboratorio, se extrajeron alícuotas para las características fisicoquímicas utilizando una metodología recomendada por la Empresa Brasileña de Investigación Agrícola (EMBRAPA), rastreando características como granulometría, materia orgánica, carbono orgánico, nitrato y nitrito, fósforo total y pH. El suelo se caracterizó como orgánico, rico en nitratos, nitritos y sales minerales, con pH (6.3), característico del ecosistema de manglar. Se realizó aislamiento, identificación de aislados MALDI-TOF (Matrix-assisted Laser Desorption/Ionization Time-Of-Flight Mass Spectrometry) y prueba de susceptibilidad antimicrobiana utilizando la metodología Kirby-Bauer. Se identificaron bacterias gramnegativas, principalmente del género Ochrobactrum y especies termotolerantes, como Escherichia coli, que se consideran patógenos que son indicadores de falta de saneamiento básico y que presentaron multirresistente in vitro a los antibióticos ensayados. Nuestro estudio fortalece la idea de futuras investigaciones para evaluar la diversidad de microorganismos presentes en los manglares para fomentar y advertir sobre la preservación y el control sanitario de los ecosistemas de manglares.

Palabras clave: Sedimento; Mangle; Resistencia Bacteriana; Fisicoquímico.

\section{Introdução}

A região do Mangue na ilha de São Luís é utilizada pela população da região para utilização como moradia, pesca, extração de mariscos e moluscos da região e bares como fonte de renda e subsistência (Martins Terceiro et al., 2013). Os manguezais exercem funções primordiais como berçário de caranguejo, meio nutritivo, centro de multiplicações de espécies animais e vegetais e fonte de recursos para comunidades costeira (Bezerra, 2008; Celeri et al., 2019; Martins Terceiro et al., 2013). 
Embora a extensão mundial dos manguezais seja pequena, cerca de 1,5\% do total das florestas tropicais e subtropicais possuem este ecossistema e seu papel ecológico é magnificado por ser um ecótono entre os sistemas marinhos e continentais, gerando diversos benefícios traduzidos por seus bens e serviços ambientais (Bryan-Brown et al., 2020). Esse ecossistema abriga grande variedade de espécies da fauna, garantindo alimento e proteção para a reprodução de diversas espécies marinhas e terrestres, atuam na dinâmica da água e sedimentos nos processos de enchentes, erosão e assoreamento, fertilizam as águas estuarinas adjacentes, participam dos processos biogeoquímicos na ciclagem de metais e são de grande importância social, econômica e cultural para as populações humanas de zona costeira (Fonsêcaet al., 2016; Moura-Fé et al., 2015).

No Maranhão, as pesquisas realizadas em áreas de manguezais íntegras e impactadas por tensores naturais e antrópicos têm considerado aspectos descritivos, qualitativos e quantitativos que revelam locais como desmatamento para construção civil e lixões ao seu arredores (Bezerra, 2008; Celeri et al., 2019; Martins Terceiro et al., 2013). Baseado a uma estimativa atual, um grama de solo pode conter 10 bilhões de bactérias, entre 400 a 700 espécies diferentes e uma densidade de biomassa de 300 a 30.000 quilogramas por hectare (Dubey et al., 2006). Em contrapartida, a grande diversidade de bactérias existentes nos solos e sedimentos podem apresentar capacidade especial em veicular genes de resistência aos antibióticos de importância clínica pela capacidade transferência horizontal genética (Von Wintersdorff et al., 2016).

A descoberta dos antibióticos representa um dos mais importantes marcos da medicina moderna. A introdução das sulfonamidas em 1930 e da penicilina na década posterior, provocaram um grande avanço no tratamento de doenças infecciosas, causando uma drástica diminuição nas taxas de mortalidade e promoção de saúde e bem-estar da sociedade (Bush et al., 2016; Coutinho et al., 2009). As décadas de 40, 50 e 60 do século passado foram marcadas pela imensa quantidade de antibióticos produzidos e rapidamente incorporados às práticas clínicas. Em contrapartida, o uso irracional de antibióticos, impulsionou em uma intensa busca por novas drogas devido o surgimento da resistência bacteriana (Araujo De Brito et al., s.d.; Guimarães et al., 2010).

$\mathrm{O}$ ecossistema de mangue, por sofrer constante impacto por ações antrópicas, pode alterar-se em aspectos como $\mathrm{pH} \mathrm{e}$ salinidade, consequentemente, favorecendo o crescimento de uma microbiota adaptada a estas condições e facilitando a transferência horizontal de genes (Barbosa, 2012; Campos et al., 2005). Diversas pesquisas têm demonstrado a relação da prevalência de bactérias resistentes em ecossistema de manguezais próximos a despejo irregular de lixo. O acúmulo de resíduo contaminantes (esgoto) ou hospitalar em ecossistema de manguezal pode contribuir no aumento de casos de infecções causadas por bactérias resistentes ou multirresistentes em ambientes desprovidos de saneamento básico ( Lima et al., 2010; Pereira et al., 2019; Silva, 2015; Soares Júnior et al., 2016).

Realizamos a identificação de microrganismos resistentes à fármacos antimicrobianos de uso clínico e a caracterização físico-química em amostras de sedimento de manguezais, localizados em São Luís, Maranhão, para obter conhecimento e a relação sobre a resistências de microrganismos isolados neste ecossistema, bem como, observar as possíveis mudanças ambientais, em virtude da sua caracterizações granulometria, matéria orgânica, carbono orgânico, os nutrientes como nitrato, nitrito, fosforo total e o $\mathrm{pH}$, através das comparações de trabalhos pré-existentes realizados na área. Este foi o primeiro trabalho a reportar o gênero Ochrobactrum na região de coleta e os dados podem subsidiar estudos futuros e gestões sustentáveis com monitoramentos na área estudada.

\section{Metodologia}

\subsection{1 Características da área de estudo}

A área de estudo localiza-se na ilha de São Luís, nas proximidades de um hospital no bairro do Jaracati, local de uma biodiversidade de manguezal do Maranhão, o mapa de localização da área dos pontos de coleta do sedimento é apresentado na Figura 1. 
Figura 1. Mapa da área de coleta.
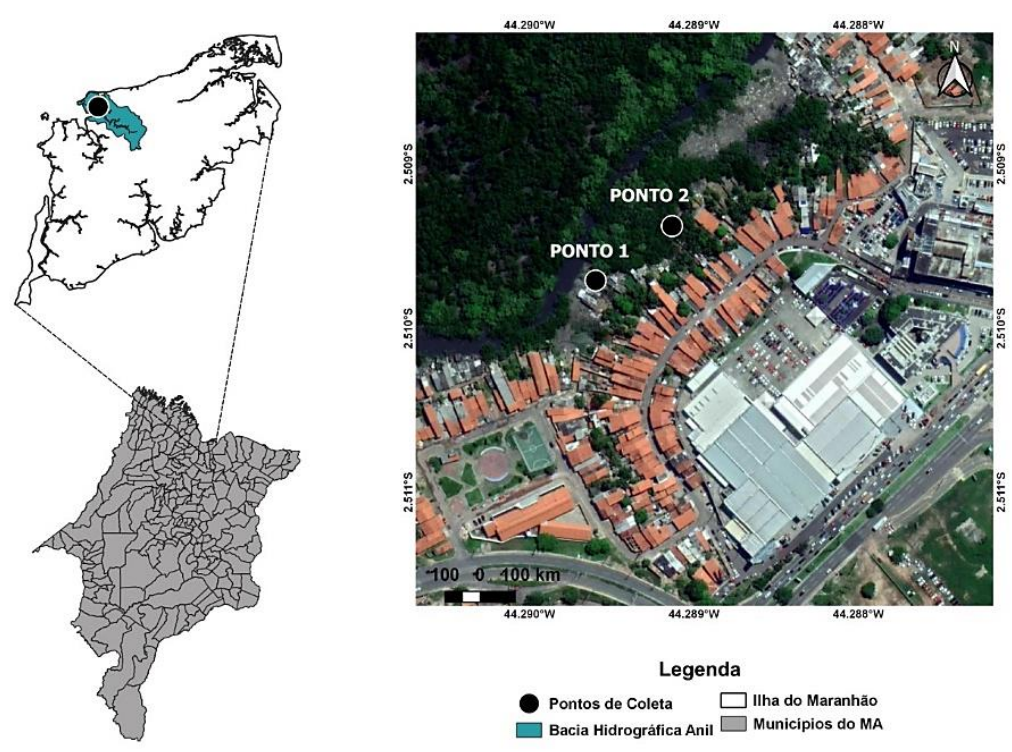

Fonte: Autores (2020).

\subsection{2 Coleta de amostras}

Foi utilizado um GPS (Global Position System) Garmin Striker ${ }^{\circledR} 4$ para demarcação da área e os pontos de coleta do solo. As características edafoclimáticas foram analisadas no ato da coleta. As amostras de solo foram denominadas de ponto 1 (P1), coordenadas $2^{\circ} 30^{\prime} 33.1^{\prime \prime S} 44^{\circ} 17^{\prime} 22.2^{\prime \prime} \mathrm{W}$ e ponto $2(\mathrm{P} 2)$, coordenadas $2^{\circ} 30^{\prime} 32.1^{\prime \prime S}$ e $44^{\circ} 17^{\prime} 19.9^{\prime \prime}$. A coleta foi realizada no período de Junho de 2019 e Agosto de 2020, respectivamente período chuvoso e seco na região. As amostras de solo foram coletadas com um trado de inox, introduzido até $15 \mathrm{~cm}$ de profundidade e conservadas em 2 a $8{ }^{\circ} \mathrm{C}$. As imagens de geoprocessamento foram obtidas e demarcadas com o auxílio do ArcGIS Pro 10.3. (ESRI Geospatial Technologies, Califórnia, EUA).

\subsection{3 Análises físico-químicas}

As amostras do solo foram coletas em triplicata do mesmo ponto de coleta em função do tamanho da área. O material foi homogeneizado e uma porção de aproximadamente 500,0g cada amostra, posteriormente foi isolada em saco plástico e acondicionadas em isopor. A partir disto, foram submetidas as respectivas análises físico-química no Laboratório de Ciências Ambientais da Universidade CEUMA (LACAM), como matéria orgânica, carbono orgânico, umidade, granulometria e concentrações dos nutrientes (nitrato e nitrito, fósforo total), conforme preconiza o Manual de Análise de Solos da Empresa Brasileira de Pesquisa Agropecuária Ministério da Agricultura, Pecuária e Abastecimento (M. L. Campos, Silva, et al., 2005; Donagem et al., 2011).

\subsection{4 Análises microbiológicas}

Um sedimento de $1,0 \mathrm{~g}$, foi adicionado em tubos contendo $9,0 \mathrm{ml}$ de solução salina $(0,9 \%)$ estéril. A amostra foi diluída em fração decimal até a diluição de $10^{-3}$. Uma alíquota de $100,0 \mu \mathrm{L}$ oriundas das amostras foram inoculadas sob a superfície de meios sólidos, Ágar MacConkey, Ágar Eosina Azul de Metileno e Cetrimide. As amostras foram espalhadas com o auxílio de uma alça de Drigalski. Após a inoculação as placas foram incubadas a temperatura de $37 \pm 1{ }^{\circ} \mathrm{C}$ por até 72 horas em estufa bacteriológica para avaliação do crescimento das colônias. Após a incubação as colônias foram contadas e os morfotipos caracterizados com auxílio de coloração de Gram.

Após o período de incubação as colônias foram quantificadas e descritas em UFC.mL ${ }^{-1}$ e as bactérias foram 
selecionadas para purificação através da metodologia de semeio por esgotamento a partir das suas características morfológicas . Para realização do teste de susceptibilidade aos antimicrobianos, foi utilizado o método proposto por Kirby e Bauer, 1966, utilizando como antibióticos de referência clínicas, meropenem, ceftadizima, amicacina, cefepima, cefoxitina, sulfametoxazol com trimetoprima, gentamicina e ciprofloxacino.

Para identificação dos grupos bacterianos e observação micro morfológica dos isolados, foi realizada a técnica de coloração de Gram, onde foi possível classificar em Gram-negativa de acordo com a coloração tintorial da parede celular. Para identificação dos isolados microbianos foi utilizado o sistema MALDI-TOF (do inglês, Matrix-Assisted Laser Desorption Ionization - Time Of Flight) e os resultados dos picos dos espectros obtidos foram comparados com a biblioteca IVD (Do inglês, in vitro Diagnostic System, Bruker Daltonics).

\subsection{5 Análises estatísticas}

Os testes de análises físico-química foram realizados em triplicata e apresentados em tabelas com média de desvio padrão. Posteriormente, foi testado se os dados brutos possuem normalidade pelo método de Shapiro-Wilk. Os dados que, por sua vez, apresentaram-se anormais, foram repetidos na avaliação. Para pontuar as diferenças significativas entre os grupos independentes testados nesta pesquisa, foi realizado o teste de Tukey com auxílio do software GraphPad Prism 8, considerando o valor $\mathrm{p} \leq 0,05$ como diferença significativa entre os testes.

\section{Resultados e discussão}

\subsection{1 Análises físico-químicas}

Dois pontos de coleta foram avaliados no período sazonal, de Junho de 2019 e Agosto de 2020, respectivamente período chuvoso e seco. Sobre os aspectos edafoclimáticos, no período chuvoso (junho) a temperatura estava em mínima de $24^{\circ} \mathrm{C}$ e máxima de $30^{\circ} \mathrm{C}$ com tempo nublado e humidade em $73 \%$. No período seco (agosto) o tempo estava limpo, com temperatura de mínima $28{ }^{\circ} \mathrm{C}$ e máxima de $32{ }^{\circ} \mathrm{C}$, umidade relativa do ar em $62,3 \%$. Para as análises físico-químicas do solo foram determinados as médias e desvio padrão dos parâmetros estudados dos pontos de coleta, representados na Tabela 1 e 2 . Aspectos como granulometria, que descrevem a proporção de partículas de dimensões distintas componentes do solo areia, silte, argila, $\mathrm{pH}$, nitrato, nitrito e fosforo total, matéria orgânica, carbono total catiônica e carbono orgânico, influência na drenabilidade, na permeabilidade do sedimento.

Tabela 1. Caracterização físico-química do sedimento de mangue no período chuvoso no mês de junho 2019.

\begin{tabular}{lll} 
Parâmetros & Ponto 1 & Ponto 2 \\
\hline $\mathrm{pH}$ & $6,34 \pm 0,005$ & $6,20 \pm 0,005$ \\
\hline $\mathrm{NO}_{3}^{-}\left(\mathrm{mg.L^{-1 }}\right)$ & $2,28 \pm 0,005$ & $2,72 \pm 0,005$ \\
\hline $\mathrm{NO}_{2}^{-}\left(\mathrm{mg} . \mathrm{L}^{-1}\right)$ & $0,39 \pm 0,005$ & $0,73 \pm 0,005$ \\
\hline $\mathrm{P}\left(\mathrm{mg} . \mathrm{L}^{-1}\right)$ & $2,70 \pm 0,005$ & $3,85 \pm 0.005$ \\
\hline Areia (\%) & $31,25 \pm 0,005$ & $32,32 \pm 0,005$ \\
\hline Silte (\%) & $36,48 \pm 0,005$ & $37,25 \pm 0,005$ \\
\hline Argila (\%) & $32,27 \pm 0,004$ & $30,42 \pm 0,003$ \\
\hline M.O (\%) & $34,35 \pm 0,004$ & $35,23 \pm 0.005$ \\
\hline C.O (\%) & $20,23 \pm 0,00$ & $24,10 \pm 0,004$ \\
\hline
\end{tabular}

Valores obtidos em triplicata com média e desvio padrão ( \pm ). $\mathrm{NO}_{3}{ }^{-}$(Nitrato), $\mathrm{NO}_{2}{ }^{-}$(Nitrito), P (Fósforo), M.O. (Matéria Orgânica), C.O. (Carbono Orgânico). Fonte: Autores (2019). 
Tabela 2. Caracterização físico-química do sedimento de mangue no período seco no mês de agosto de 2020.

\begin{tabular}{lll} 
Parâmetros & Ponto 1 & Ponto 2 \\
\hline $\mathrm{pH}$ & $4,1 \pm 0,005$ & $5,9 \pm 0,005$ \\
\hline $\mathrm{NO}_{3}{ }^{-}\left(\mathrm{mg} . \mathrm{L}^{-1}\right)$ & $1,86 \pm 0,005$ & $1,75 \pm 0,005$ \\
\hline $\mathrm{NO}_{2}^{-}\left(\mathrm{mg} . \mathrm{L}^{-1}\right)$ & $0,31 \pm 0,005$ & $0,55 \pm 0,005$ \\
\hline $\mathrm{P}\left(\mathrm{mg} . \mathrm{L}^{-1}\right)$ & $1,98 \pm 0,005$ & $3,6 \pm 0,005$ \\
\hline Areia (\%) & $29,8 \pm 0,005$ & $30,67 \pm 0,005$ \\
\hline Silte (\%) & $39,3 \pm 0,005$ & $35,88 \pm 0,003$ \\
\hline Argila (\%) & $30,9 \pm 0,004$ & $33,45 \pm 0,005$ \\
\hline M.O (\%) & $33,68 \pm 0,004$ & $34,88 \pm 0,005$ \\
\hline C.O (\%) & $22,43 \pm 0,001$ & $21,11 \pm 0,004$ \\
\hline
\end{tabular}

Valores obtidos em triplicata com média e desvio padrão ( \pm ). $\mathrm{NO}_{3}^{-}$(Nitrato), $\mathrm{NO}_{2}^{-}$(Nitrito), P (Fósforo), M.O. (Matéria Orgânica), C.O. (Carbono Orgânico). Fonte: Autores (2020).

O perfil obtido das análises físico-químicas do solo foi compatível com características encontradas frequentemente em zona de manguezais (Martins Terceiro et al., 2013; Rocha, 2008; Soares Júnior et al., 2016). Observando-se os valores do nitrito e nitrato dos pontos 1 e 2, pode-se observar um maior depósito destes produtos orgânicos, que pode ser devido ao maior acúmulo de resíduo hospitalar e mediação bioquímica pela presença de bactérias no solo de ecossistema manguezal contaminados (Celeri et al., 2019; Rocha, 2008).

Houve uma variação significativa para o fosforo em valores totais, variando entre os pontos durante o período chuvoso $\left(3,85\right.$ a 2,70 mg. $\left.\mathrm{L}^{-1}\right)$ e seco $\left(1,98\right.$ a 3,6 mg.L $\left.\mathrm{L}^{-1}\right)$, esta alteração pode ser explicada pelo regime de chuvas, maré e salinidade (Cuzzuol et al., 2012). A granulometria nas amostras do sedimento no período chuvoso e seco variaram entre os pontos de coleta, portanto, foram classificados como sendo areia à fina à siltosa à argilosa, porque podem influenciar as condições ambientais, a fração de argila e silte predominou na quase totalidade dos pontos (Berrêdo et al., 2008).

Os solos de manguezal costumeiramente são fontes de matéria orgânica pela deposição de material em decomposição. Durante a avaliação de matéria orgânica nos pontos em estudo, foi observado maior concentração de matéria orgânica no período chuvoso, bem como maiores valores de carbono orgânico. Estes elementos são essenciais para o ecossistema e favorecem o crescimento de microrganismos (Barbosa, 2012; Rocha, 2008). O aumento da disponibilidade da matéria orgânica fortalece a proliferação de microrganismos patogênicos, podendo elevar as chances de prejuízos pela contaminação de aquíferos subterrâneos e incidência de doenças infeciosas nas comunidades locais (Martins Terceiro et al., 2013; Silva et al., 2017)

Os resultados do teor de carbono nas frações húmicas dos sedimento estudados, corroborando com estudos realizados por Campos e colaboradores (2012) mostram que os ambientes que contam com a presença de resíduo vegetal tiveram maior teor de carbono orgânico. O resíduo vegetal que permanece na superfície do solo é uma fonte importante de carbono, nitrogênio, e outros elementos que contribuem na manutenção dos níveis de matéria orgânica do solo e na ciclagem de nutrientes. Constata uma intervenção antrópica e aos pontos abaixo de 10\%, são considerados solos de minerais de predominância de sílicas e argila com compostos de adubação da região. Blainski e colaboradores (2012) avaliaram a influência vegetal e de resíduos sobre a densidade, porosidade e outros atributos físicos de um solo franco-arenoso sob plantio direto e constataram uma melhoria considerável na qualidade física do solo, com diminuição da densidade, em contraste ao aumento de densidade nos tratamentos sem cobertura vegetal. 


\subsection{Isolamento de microrganismos}

Foram isoladas 6 colônias de bacterianas Gram-negativas de amostras P1 e P2 de sedimentos do riacho de mangues na grande ilha de São Luís, este isolados e suas respectivas unidades formadoras de colônia (UFC) foram representados detalhadamente na Tabela 3. Houve crescimento de uma importante bactéria clínica e termotolerante, a Escherichia coli. Esta espécie desenvolveu-se em baixas diluições e para ambos os pontos de coleta. Foi isolado também bactérias do gênero Ochrobactrum e espécies como Citrobacter freundii em ambos os pontos de análise.

Segundo Dubey e colaboradores (2006) o quantitativo microbiano maior se deve das alterações físicas e químicas, fatores bióticos e abióticos, possibilitando a prevalência de maior quantidade do grupo microbiano, corroborando com nossos resultados, pois após a contagem, constatou-se que a quantidade de microrganismos no ponto 1 é maior que no ponto 2 . A atividade microbiana é responsável por grande parte das transformações nutricionais ocorridas no ecossistema manguezal, como foi observado nos parâmetros físico-químicos.

Tabela 3. Isolados bacterianos oriundos das amostras coletadas em período seco.

\begin{tabular}{llll} 
Ponto & UFC/mL & Escherichia coli & Citrobacter freundii \\
\hline \multirow{2}{*}{$\mathbf{1}$} & $10^{-1}$ & $6,70.10^{2}$ & $9,30.10^{2}$ \\
\cline { 2 - 4 } & $10^{-2}$ & $1,11.10^{2}$ & $2,20.10^{2}$ \\
\cline { 2 - 4 } & $10^{-3}$ & $3,10.10^{3}$ & $1,28.10^{3}$ \\
\cline { 2 - 4 } $\mathbf{2}$ & $10^{-1}$ & $1,30.10^{2}$ & $3,52.10^{2}$ \\
\cline { 2 - 4 } & $10^{-2}$ & $3,0.10^{2}$ & $3,66.10^{2}$ \\
\cline { 2 - 4 } & $10^{-3}$ & $1,14.10^{3}$ & $2,0.10^{3}$ \\
\hline
\end{tabular}

Legenda: UFC - Unidades Formadoras de Colônias. Fonte: Autores (2021).

\subsection{Identificação de microrganismos}

O gênero Ochrobactrum foi o mais prevalente nas amostras isoladas, dentre este as espécies deste gênero, pode-se citar $O$. intermedium e $O$. tritici. As bactérias detectadas em nosso estudo são responsáveis por infecções adquiridas no ambiente comunitário e em hospitais, causando inúmeras patologias, dentre elas as mais recorrentes são infecções do trato gastrointestinal, infecções nosocomiais, no trato respiratório e infecções da corrente sanguínea e já houve detecção destes micróbios isolado de caranguejos conhecidos popularmente como "Uçá", oriundos de mangue e que são bastantes consumidos na grande ilha de São Luís do Maranhão (Alonso et al., 2017; Chen et al., 2002; Lupo et al., 2013; Metila, 2007; Thurm et al., 1994).

A veiculação de patógenos bacterianos como por exemplo linhagens das espécies Serratia marcescens e O. antropi, no ambiente aquático e sua deposição em sedimentos de rios como em áreas de manguezais, retratam o grande impacto destes reservatórios naturais na disseminação de microrganismos oportunistas (Lu et al., 2010). As espécies $O$. anthropi e $O$. intermedium são descritos como patógenos oportunistas, afetando principalmente indivíduos imunocomprometidos (Dias et al., 1985; Von Wintersdorff et al., 2016).

Apesar de ser comum encontrar espécies bacterianas em amostras ambientais, algumas contaminações se deve a instalação de clínicas e hospitais na região, fazendo esse ambiente sofrer muitos impactos, como por exemplo, o lançamento de esgoto e poluentes direto no solo, sem devidos cuidados no ambiente (Alonso et al., 2017).

Figura 2. Caracterização da morfologia de uma espécie Gram-negativa isolada de sedimento de mangue em São Luís, Maranhão. Caracterização da morfológica de uma bactéria Gram Negativa figura (A) a partir de isolamento (B) e teste de 
susceptibilidade aos antimicrobianos em C, D e E.

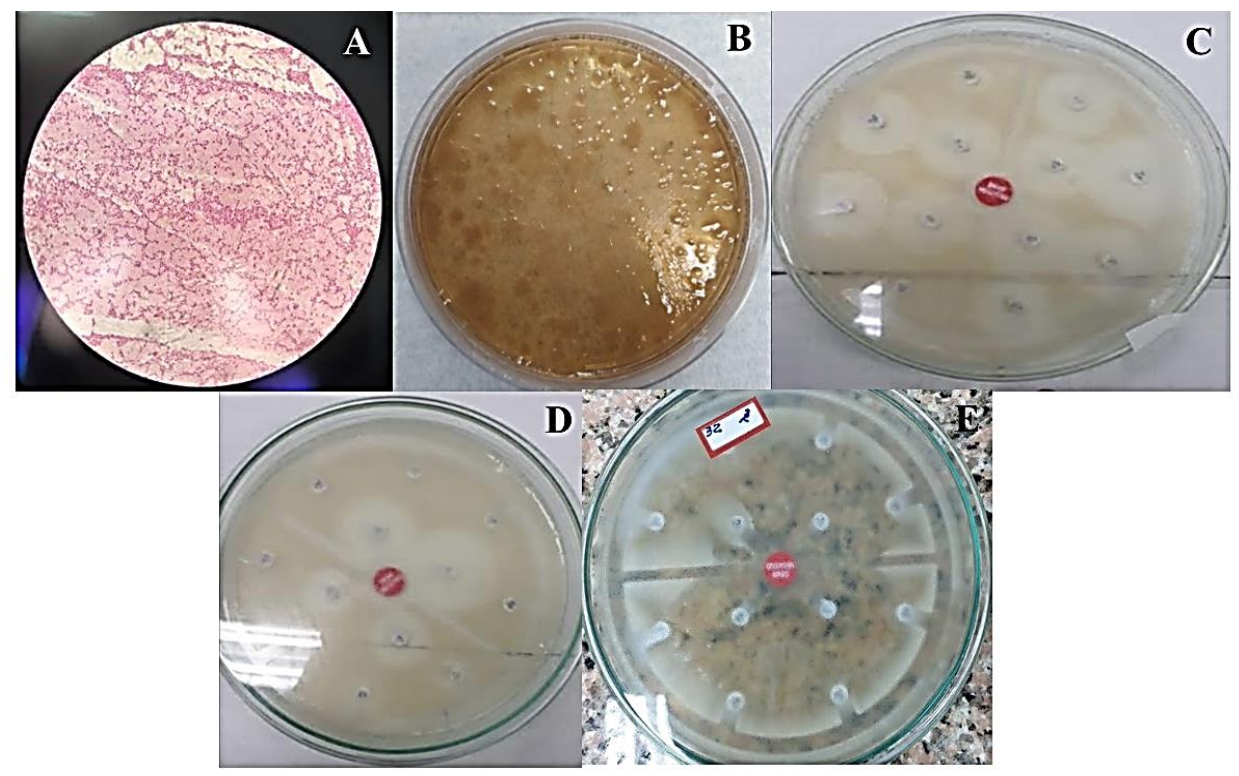

Fonte: Autores (2020).

\subsection{Perfil de susceptibilidade aos antimicrobianos}

Neste estudo foram realizados testes de suscetibilidade às drogas antimicrobianas pelo método de disco-difusão. Nos ensaios foram utilizadas 8 drogas diferentes para 6 isolados de bactérias Gram-negativas e são demonstrados na Figura 3. O perfil de susceptibilidade aos antimicrobianos dos isolados foram de $100 \%(\mathrm{n}=6)$ para meropenem, seguidos de 83,3\% $(\mathrm{n}=5)$ isolados resistentes a ceftadizima e cefepima. Em relação ao perfil de sensibilidade observou-se que $100 \%$ (n=6) dos isolados foram sensíveis ao fármaco ciprofloxacino, $83,3 \%$ (n=5) sensíveis a gentamicina e sulfametoxazol com trimetoprima, seguidos de $66,6 \%$ (n=4) sensíveis a amicacina e cefotaxima.

Figura 3. Perfil de suscetibilidade aos antimicrobianos de isolados bacterianos de sedimento de manguezal na ilha de São Luís do Maranhão.

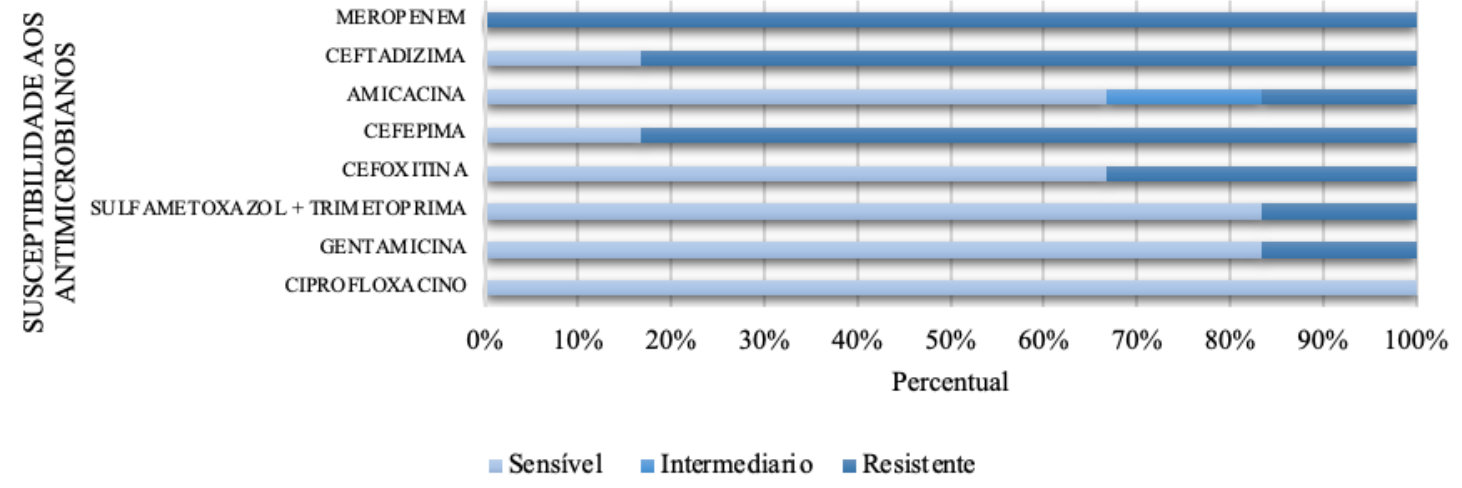

Fontes: Autores (2020).

A resistência antimicrobiana é considerada um problema de saúde mundial. Com base nos resultados referentes nesse estudo, podemos observar que bactérias de cunho ambiental, isoladas de ecossistema de mangue, apresentam resistência a mais de um fármaco. Vários estudos já apontaram bactérias resistentes isoladas de ambientes aquáticos (Rocha, 2008; Soares Júnior et al., 2016; Zhao et al., 2019). A espécie Ochrobactrum anthropi (Sinônimo, Brucella anthropi) apresentou resistência a antimicrobianos da classe dos $\beta$-lactâmicos e cefalosporinas de primeira, segunda e terceira geração. A dispersão dessas drogas 
no ambiente e decorrente das ações antrópicas do homem, com ao poluição, tem como consequência o surgimento de bactérias resistentes (Sivagami et al., 2018).

Nossos resultados corroboram com estudos realizados por Zhao e colaboradores (2019), que também isolou diferentes espécies bacterianas de mangues nas proximidades do rio (área de manguezal), como bactérias Gram-negativas, $O$. antropi, $O$. intermedium e $O$. tritici, S. marcescens. Também, foram detectadas as espécies Stenotrophomonas maltophilia, Acinetobacter johnsoni, Acinetobacter towneri, Pseudomonas monteilii, Pseudomonas putida, Rhizobium radiobacter, Sphingomonas paucimobili. A maioria das espécies bacterianas detectadas nas amostras de sedimento do rio Anil são patógenos oportunistas para seres humanos e podem acometer doenças infeciosas graves (Chen et al., 2002; Dias et al., 1985; Thurm et al.,1994; Zhao et al., 2019).

Foi observado que a disseminação de bactérias antibiótico-resistentes pode ocorrer em ambiente de ecossistema de mangue que são alvos de depósitos de resíduos contaminantes por falta de saneamento básico (Soares Júnior et al., 2016). Nos últimos anos, tem sido observado um crescimento vertiginoso nos casos de resistência aos antibióticos, em uma taxa que o desenvolvimento de novos agentes antibacterianos não tem acompanhado (Machado et al., 2020). Sabe-se que o mecanismos de disseminação de genes de resistência entre as bactérias são pela utilização de genes capazes de se transpor (transposons) transferidos por Pilus sexual, estruturas não essenciais, mas frequentemente encontradas em bactérias Gram-negativas (Bush \& Bradford, 2016).

O surgimento de cepas resistentes no ambiente pode promover maior gasto com antibióticos e internação hospitalar. Segundo Arruda e colaboradores (2019), os carbapenêmicos pertencem a uma classe de antibióticos de amplo espectro conhecidos também como enzimas $\beta$-lactamases de espectro estendido (ESBL). Algumas cepas bacterianas podem codificar genes que codificam ESBL e, para que ocorra a eficácia de carbapenêmicos pode utilizar-se de técnicas de combinações de antimicrobianos, como cefalosporinas e carbapenêmicos (Arruda et al., 2019).

A oportunidade de bactérias em um ambiente rico em matéria orgânica e minerais pode favorecer a contaminação de um ecossistema e elevar as chances de contaminação comunitária, disseminação de patógenos, elevação da morbidade e mortalidade de comunidades sem acesso a saneamento básico em comunidades ribeirinhas (Bezerra, 2008; Gomes, 2001).

\section{Considerações Finais}

Com base nas caracterizações dos sedimentos do mangue nesta pesquisa, o solo foi classificado como solo úmido, salgado, rico em matéria orgânica, principalmente em período chuvoso. Foi observado também uma elevada presença de nitrito que, frequentemente, está associado a presença de bactérias. Foi possível isolar bactérias, como Ochrobactrum intermedium, Ochrobactrum tritici, Escherichia coli e Citrobacter freundii. Os isolados bacterianos apresentaram multirresistência a diferentes classes de antibióticos testados. Portanto, mais investigações sobre a evolução e disseminação da resistência a antibióticos em bactérias ambientais são necessárias para entender e prevenir o surgimento de micróbios de importância clínica em ambiente sem saneamento e urbano.

\section{Referências}

Alonso, C. A., Kwabugge, Y. A., Anyanwu, M. U., Torres, C., \& Chah, K. F. (2017). Diversity of Ochrobactrum species in food animals, antibiotic resistance phenotypes and polymorphisms in the blaOCH gene. FEMS Microbiology Letters, 364(17). https://doi.org/10.1093/femsle/fnx178

Araujo De Brito, M., Benedito, ;, \& Cordeiro, C. (n.d.). Necessidade de novos antibióticos The need of new antibiotics. 2012. Retrieved February 1, 2022, from www.imshealth.com/portal/site/ims

Arruda, J. M., Siqueira, C., Souza, V., Silva, F., Silva, L., Santos, J., Cipriano, K., Dias, D., \& Faro, L. (2019). Bibliographic review of Beta-lactam 
antibiotics. Revista Saúde Em Foco, 11, 982-995. http://www.icb.usp.br/bmm/mariojac/index.php?option=com_content\&view=article\&id=47\&I

Barbosa, S. C. de B. 1988-. (2012). Determinação de resíduos de pesticidas em produtos de origem vegetal por GC-ECD. https://repositorio.ul.pt/handle/10451/7448

Berrêdo, J. F., Costa, M. L., \& Progene, M. D. P. S. (2008). Efeitos das variações sazonais do clima tropical úmido sobre as águas e sedimentos de manguezais do estuário do rio Marapanim, costa nordeste do Estado do Pará. Acta Amazonica, 38(3), 473-482. https://doi.org/10.1590/S0044-59672008000300012

Bezerra, D. da S. (2008). O Ecossistema Manguezal em Meio Urbano no Contexto de Políticas Públicas de Uso e Ocupação do Solo na Bacia do Rio Anil , São Luis, Maranhão. [Universidade Federal do Maranhão]. http://tedebc.ufma.br:8080/jspui/handle/tede/1077

Blainski, É., Tormena, C. A., Guimarães, R. M. L., \& Nanni, M. R. (2012). Influence of soil cover on the soil physical quality of an Oxisol in no-tillage. Revista Brasileira de Ciencia Do Solo, 36(1), 79-87. https://doi.org/10.1590/s0100-06832012000100009

Bryan-Brown, D. N., Connolly, R. M., Richards, D. R., Adame, F., Friess, D. A., \& Brown, C. J. (2020). Global trends in mangrove forest fragmentation. Scientific Reports, 10(1). https://doi.org/10.1038/S41598-020-63880-1

Bush, K., \& Bradford, P. A. (2016). $\beta$-Lactams and $\beta$-Lactamase Inhibitors: An Overview. Cold Spring Harbor Perspectives in Medicine, 6(8). https://doi.org/10.1101/CSHPERSPECT.A025247

Campos, M. C. C., Ribeiro, M. R., Júnior, V. S. de S., Filho, R. R., \& Almeida, M. C. (2012). Topossequência de solos na transição campos naturais-floresta na região de Humaitá, Amazonas. Acta Amazonica, 42(3), 387-398. https://doi.org/10.1590/S0044-59672012000300011

Campos, M. L., Da Silva, F. N., Furtini Neto, A. E., Guimarães Guilherme, L. R., Marques, J. J., \& Antunes, A. S. (2005). Determination of cadmium, copper, chromium, nickel, lead and zinc in rock phosphates. Pesquisa Agropecuaria Brasileira, 40(4), 361-367. https://doi.org/10.1590/s0100-204x2005000400007

Campos, M. L., Silva, F. N. da, Furtini Neto, A. E., Guilherme, L. R. G., Marques, J. J., \& Antunes, A. S. (2005). Determinação de cádmio, cobre, cromo, níquel, chumbo e zinco em fosfatos de rocha. Pesquisa Agropecuária Brasileira, 40(4), 361-367. https://doi.org/10.1590/s0100-204x2005000400007

Celeri, M. J., Mendes, L. E. T., Lima, R. M. B. de F., \& Vasconcelos, T. da R. (2019). A cidade, o mangue e os resíduos sólidos: estudo de caso do Manguezal Vinhais, São Luís - MA/ The city, the mangue and the solid waste:The Vinhais Mangrove case in the city of São Luís -MA. Geografia Em Atos (Online), 3(10), 163-186. https://doi.org/10.35416/geoatos.v3i10.5710

Chen, Y. S., Wong, W. W., Fung, C. P., Yu, K. W., \& Liu, C. Y. (2002). Clinical features and antimicrobial susceptibility trends in Citrobacter freundii bacteremia. Journal of Microbiology, Immunology, and Infection = Wei Mian Yu Gan Ran Za Zhi, 35(2), 109-114. https://europepmc.org/article/med/12099331

Coutinho, H. D. M., Costa, J. G. M., Lima, E. O., Falcão-Silva, V. S., \& Siqueira, J. P. (2009). Herbal therapy associated with antibiotic therapy: Potentiation of the antibiotic activity against methicillin - Resistant Staphylococcus aureus by Turnera ulmifolia L. BMC Complementary and Alternative Medicine, 9. https://doi.org/10.1186/1472-6882-9-13

Cuzzuol, G. R. F., \& Rocha, A. C. (2012). Interação do regime hídrico com as relações nutricionais em ecossistema manguezal. Acta Botanica Brasilica, 26(1), 11-19. https://doi.org/10.1590/S0102-33062012000100003

de Lima Grisi, T. C. S., \& Gorlach-Lira, K. (2010). The abundance of some pathogenic bacteria in mangrove habitats of Paraiba do Norte estuary and crabmeat contamination of mangrove crab Ucides cordatus. Brazilian Archives of Biology and Technology, 53(1), 227-234. https://doi.org/10.1590/S151689132010000100028

Dias, J. C., \& Hofer, E. (1985). Bactérias gram negativas resistentes a antimicrobianos em alimentos. Memórias Do Instituto Oswaldo Cruz, 80(4), 411-421. https://doi.org/10.1590/S0074-02761985000400006

Donagem, G. K., Campos, D. V. B. de, Calderano, S. B., Teixeira, W. G., \& Viana, J. H. M. (2011). Manual de métodos de análise de solo. - Portal Embrapa. https://www.embrapa.br/busca-de-publicacoes/-/publicacao/990374/manual-de-metodos-de-analise-de-solo

Dubey, S. K., Tripathi, A. K., \& Upadhyay, S. N. (2006). Exploration of soil bacterial communities for their potential as bioresource. Bioresource Technology, 97(17), 2217-2224. https://doi.org/10.1016/J.BIORTECH.2005.06.008

Fonsêca, I. L. A., \& Mochel, F. R. (2016). Fitomassa aérea de um manguezal no estuário do rio dos cachorros, são luís, maranhão, brasil. In BOLETIM DO $\begin{array}{llllll}\text { laboratório de hidrobiologia } & \text { Bol. } & \text { Lab. Hidrobiol } & \text { (Vol. } & \text { 26, Issue } & \text { 1, }\end{array}$ http://www.periodicoseletronicos.ufma.br/index.php/blabohidro/article/view/5441

Gomes, C. de M. T. [UNESP]. (2001). Degradação ambiental urbana e qualidade de vida nas áreas de manguezais ocupadas por palafitas em São Luís - MA. Aleph, 73 f. : il. https://repositorio.unesp.br/handle/11449/89827

Guimarães, D. O., Da Silva Momesso, L., \& Pupo, M. T. (2010). Antibióticos: Importância terapêutica e perspectivas para a descoberta e desenvolvimento de novos agentes. In Quimica Nova (Vol. 33, Issue 3, pp. 667-679). Sociedade Brasileira de Química. https://doi.org/10.1590/S0100-40422010000300035

Lu, S. Y., Zhang, Y. L., Geng, S. N., Li, T. Y., Ye, Z. M., Zhang, D. S., Zou, F., \& Zhou, H. W. (2010). High diversity of extended-spectrum beta-lactamaseproducing bacteria in an urban river sediment habitat. Applied and Environmental Microbiology, 76(17), 5972-5976. https://doi.org/10.1128/AEM.0071110/SUPPL_FILE/SUPPLEMENT_TABLE_1.ZIP

Lupo, A., Papp-Wallace, K. M., Sendi, P., Bonomo, R. A., \& Endimiani, A. (2013). Non-phenotypic tests to detect and characterize antibiotic resistance mechanisms in Enterobacteriaceae. Diagnostic Microbiology and Infectious Disease, 77(3), 179-194. https://doi.org/10.1016/J.DIAGMICROBIO.2013.06.001

Machado, E. C., Leal, C. D., Coelho, B. L., Chernicharo, C. A. de L., \& de Araújo, J. C. (2020). Detecção e quantificação de bactérias resistentes aos antibióticos ampicilina e cloranfenicol em estações de tratamento de esgoto doméstico. Engenharia Sanitaria e Ambiental, $25(6)$, 847-857. https://doi.org/10.1590/S1413-4152202020180001 
Martins Terceiro, A., Jethro, J., \& Santos, S. (2013). Caracterização da sociedade, economia e meio ambiente costeiro atuante à exploração dos manguezais no estado do maranhão. Revista de Administração e Negócios Da Amazônia, 5(3), 94-111.

Metila, V. De. (2007). Análise microbiológica do caranguejo Uçá, Ucides cordatus (Linnaeus, 1963), como bioindicador ambiental dos manguezais dos Rio Paciência, Ilha de São Luís-MA. Ecologia. http://www.ufsc.br/.

Moura-Fé, M. M., Albuquerque, A. G. B. M., Freitas, E. M. N., \& Barbosa, W. R. (2015). A Proteção do Ecossistema Manguezal pela Legislação Ambiental Brasileira. GEOgraphia, 17(33), 126-153. https://doi.org/10.22409/GEOGRAPHIA2015.V17I33.A13700

Pereira, E. B., Barros, F. D., \& Hollanda, L. M. de. (2019). Bioprospecção de bactérias produtoras de antimicrobianos isoladas dos solos de diferentes manguezais do estado de Sergipe. Semana de Pesquisa e Extensão Da Universidade Tiradentes - SEMPESq-SEMEX, O(21). https://eventos.set.edu.br/sempesq/article/view/12768

Rocha, L. L. (2008). Estudo de comunidades bacterianas de solos de manguezal da Barra Grande, Icapui - Ce e seleção de cepas com potencial para degradar hidrocarbonetos. http://www.repositorio.ufc.br/handle/riufc/4923

Silva, M. R. C., Silva, L. V. da, Barreto, L. N., Rodrigues, E. H. C., Miranda, R. de C. M. de, Bezerra, D. S., \& Pereira, D. C. A. (2017). Qualidade da Água da Bacia do Rio Pindaré, nos trechos correspondentes aos Municípios de Pindaré- Mirim, Tufilândia e Alto Alegre no Estado do Maranhão. Águas Subterrâneas, 31(4), 347-354. https://doi.org/10.14295/RAS.V31I4.28929

Silva, W. D. E. M. (2015). Metais pesados em solos de manguezais em estuários da bacia Paraíba, Nordeste do Brasil.

Sivagami, K., Vignesh, V. J., Srinivasan, R., Divyapriya, G., \& Nambi, I. M. (2018). Antibiotic usage, residues and resistance genes from food animals to human and environment: An Indian scenario. Undefined, 8(1). https://doi.org/10.1016/J.JECE.2018.02.029

Soares Júnior, F. L., Fernando, ;, Andreote, D., João, ;, Da Silva, L., Júlio, ;, De Queiroz, F., \& De Melo, I. S. (2016). Avaliação da resistência a antibióticos de bactérias isoladas da água de viveiros de camarão. http://www.alice.cnptia.embrapa.br/handle/doc/15750

Thurm, V., \& Gericke, B. (1994). Identification of infant food as a vehicle in a nosocomial outbreak of Citrobacter freundii: epidemiological subtyping by allozyme, whole-cell protein and antibiotic resistance. Journal of Applied Bacteriology, 76(6), 553-558. https://doi.org/10.1111/J.1365-2672.1994.TB01652.X

Von Wintersdorff, C. J. H., Penders, J., Van Niekerk, J. M., Mills, N. D., Majumder, S., Van Alphen, L. B., Savelkoul, P. H. M., \& Wolffs, P. F. G. (2016). Dissemination of antimicrobial resistance in microbial ecosystems through horizontal gene transfer. Frontiers in Microbiology, 7(FEB), 173. https://doi.org/10.3389/FMICB.2016.00173/BIBTEX

Zhao, H., Yan, B., Mo, X., Li, P., Li, B., Li, Q., Li, N., Mo, S., Ou, Q., Shen, P., Wu, B., \& Jiang, C. (2019). Prevalence and proliferation of antibiotic resistance genes in the subtropical mangrove wetland ecosystem of South China Sea. MicrobiologyOpen, 8(11), 871. https://doi.org/10.1002/MBO3.871 